\title{
Advances in understanding and treating persecutory delusions: a review
}

\author{
Daniel Freeman • Philippa Garety
}

Received: 8 June 2014 / Accepted: 30 June 2014/Published online: 9 July 2014

(C) The Author(s) 2014. This article is published with open access at Springerlink.com

\begin{abstract}
Purpose Persecutory delusions are a central psychotic experience, at the severe end of a paranoia spectrum in the general population. The aim of the review is to provide an introduction to the understanding of persecutory delusions, highlight key putative causal factors that have the potential to be translated into efficacious treatment, and indicate future research directions.

Methods A narrative literature review was undertaken to highlight the main recent areas of empirical study concerning non-clinical and clinical paranoia.

Results Six main proximal causal factors are identified: a worry thinking style, negative beliefs about the self, interpersonal sensitivity, sleep disturbance, anomalous internal experience, and reasoning biases. Each has plausible mechanistic links to the occurrence of paranoia. These causal factors may be influenced by a number of social circumstances, including adverse events, illicit drug use, and urban environments.

Conclusions There have been numerous replicated empirical findings leading to a significant advance in the understanding of persecutory delusions, now beginning to be translated into cognitive treatments. The first trials specifically focussed on patients who have persecutory delusions in the context of psychotic diagnoses are occurring. Initial evidence of efficacy is very promising.
\end{abstract}

D. Freeman $(\bowtie)$

Department of Psychiatry, University of Oxford, Warneford Hospital, Oxford OX3 7JX, UK

e-mail: Daniel.Freeman@psych.ox.ac.uk

P. Garety

King's College London, London, UK
Keywords Delusions $\cdot$ Persecutory $\cdot$ Schizophrenia Psychosis · Paranoia

\section{Introduction}

'My neighbours are spreading nasty rumours and are tormenting me'

'MI5, MOSSAD, and the police are trying to get me and torture me'

'An evil spirit is out to kill me' [1]

Two distressing concerns are at the heart of persecutory delusions: harm is going to occur and others intend it [2]. Almost half of individuals with persecutory delusions have levels of psychological well-being in the lowest $2 \%$ of the general population [3]. The delusions are typically accompanied by anxiety [4], depression [5], and disturbed sleep [6]. A personal account by Weiner [7] notes: 'What I remember most is how disoriented and frightened I felt.' At first episode of psychosis, over $70 \%$ of patients have a persecutory delusion $[8,9]$. It is the type of delusion most likely to be acted upon [10]. Persecutory delusions are a common, clinically important, psychotic experience, for which treatments need to be significantly improved. We advocate the approach of understanding the causes to translate this knowledge into efficacious treatment [11].

Increasingly it is being recognised that persecutory delusions are at the extreme end of a paranoia spectrum. It is another example, more widely accepted for common mental health problems, of a quantitative trait in the general population [12,13]. As illustrated in Fig. 1, there is an exponential distribution of paranoid thoughts in the general population $[14,15]$. This distribution of paranoia has even been found in children [16]. Many people have a few paranoid thoughts, and a few have many. Paranoia in the 


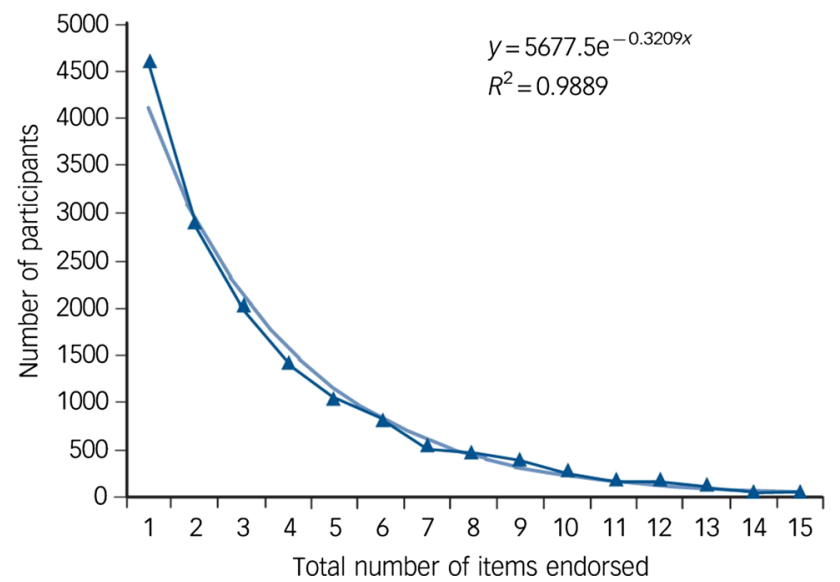

Fig. 1 The distribution of total paranoia scores in the general population [15]

general population is associated with poorer physical health, suicidal ideation, and weaker social cohesion [17]. Only recently has the heritability of paranoia in the general population been estimated. In a study of five thousand adolescent twin pairs, it was found that $50 \%$ of the variability in levels of paranoia in the population is due to genes [18]. Identifying the genes is likely to prove difficult [19], though of course the heritability estimate indicates that the environment has an equally important role in the occurrence of paranoia. Paranoia in adulthood generally decreases slightly with age, and though there may be content differences the rates appear similar in men and women [17].

Study of individual psychotic experiences has gained ground because of the evidence that the main diagnoses of psychosis, such as schizophrenia, schizo-affective disorder, and delusional disorder, do not capture single disorders. Despite their longevity of use, the diagnoses may prove an obstacle in the advancement of the understanding and treatment of the difficult experiences for which patients require help. The empirical research indicates that within these diagnoses are multiple independent experiences, such as paranoia, hallucinations, grandiosity, thought disorder, and anhedonia [13, 20-22]. A research approach, particularly adopted by cognitive psychology, has been to try to explain these single psychotic experiences. We note that most causes are 'inus conditions'- 'an insufficient but nonredundant part of an unnecessary but sufficient condition' [23]. Paranoia arises from a combination of causes, with each causal factor only increasing the probability of such fears occurring. This review highlights our perspective on the established findings, the most promising directions, and key research questions. The empirical evidence here is synthesised from an updated search continuing on from our three earlier systematic literature reviews of delusions [24-26].

\section{A worry thinking style}

'... sit and think. Then get paranoider and paranoider and paranoider and paranoider' [27]

Worry brings implausible ideas to mind, keeps them there, and increases the distress that they cause. It is therefore a plausible factor in the occurrence of paranoid thinking [28]. The evidence to support this position has been accumulating. A longitudinal national epidemiological survey showed that the presence of worry predicts new inceptions of paranoid thoughts over 18 months [29]. Worry predicts the persistence of existing non-clinical paranoia $[29,30]$. Those who tend to adopt a worry thinking style are also more likely to experience paranoia in an experimental setting [31, 32]. Rates of worry in patients with persecutory delusions are comparable to those seen in patients with generalised anxiety disorder [28, 3335]. Levels of rumination are also high in patients with persistent persecutory delusions [36]. An experience sampling study has shown that a period of worry precedes the occurrence of delusional ideation [37]. Importantly, the level of worry in patients predicts the persistence of persecutory delusions over the following months [5, 38].

These theoretical studies led to two pilot clinical trials that attempted to reduce levels of worry in patients with persecutory delusions. The worry interventions address the tendency to react to troubling thoughts with worry and do not dispute the content of persecutory delusions. The initial evidence was encouraging, indicating that reducing worry may lead to reductions in the delusions [39, 40]. This has now been rigorously tested by Freeman and colleagues [40] in the Worry Intervention Trial, the first major randomised controlled trial specifically for patients with persecutory delusions. 150 patients with persistent persecutory delusions were randomised to a six session worry reduction intervention in addition to standard care or to standard care. Assessments were carried out blind and the follow-up rate was very high. The CBT for worry intervention led to significant reductions in worry and the persecutory delusions. Changes in worry mediated the majority of the change in the delusions. There were also significant improvements in well-being, and reductions in rumination, overall psychiatric symptoms and general levels of paranoia. This is convincing evidence for the importance of a worry thinking style causing the persistence of persecutory delusions and the strongest demonstration to date of the advances in understanding being translated into treatment. Treatment refinement is likely to benefit from studies that determine the mechanisms underlying worry in patients with delusions. 


\section{Negative thoughts about the self}

'After university, however, I failed to really get a good start to my career, I was working part time and living with my parents, I had no clue about what I really wanted to do, and because I had no money, I couldn't go out very much... I began to be under the impression that I had some sort of social handicap... Eventually, I was convinced that when I was out on the street, everyone who saw me instantly knew I had some sort of social handicap. It actually started to feel as if everybody who met me pretended to treat me normally and then laughed at me behind my back once I'd gone' [41].

The view encapsulated in the paranoia hierarchy (see Fig. 2) [14] is that feeling negative about the self can lead to feelings of being different, apart, inferior and hence vulnerable. Paranoia is likely to flourish when an individual perceives him or herself as potentially vulnerable. Two longitudinal patient studies have shown that negative thoughts about the self predict the persistence of persecutory delusions [5, 42]. In the largest of these, 301 patients with psychosis were assessed three times over a year [42]. Structural equation modelling indicated that negative cognition led to paranoid thinking, with little evidence for the reverse direction. Three recent systematic reviews indicate that paranoia is associated directly with negative self-concepts, without the need to evoke defensive processes [26, 43, 44]. Individuals with persecutory delusions may actually be excessively critical of themselves [45]. A recent experimental study manipulated self-esteem in people vulnerable to paranoid thoughts [46]. The

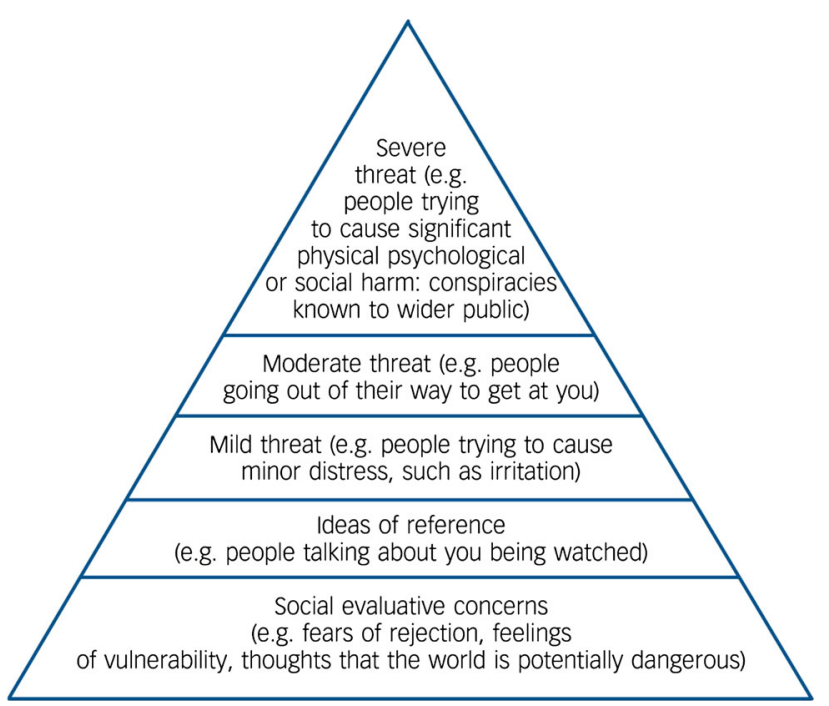

Fig. 2 The paranoia hierarchy [14] participants entered a virtual social world twice: once at their normal height, once at a reduced height. Height is associated with social status, so it was predicted that reducing height would lead to lower self-esteem. It was found that reducing height led to more negative thoughts about the self in relation to others and this explained an increase in paranoia. Another experimental study has indicated that a compassion focussed technique reduces the occurrence of paranoid ideation during recall of a distressing memory [47].

The evidence for an association of persecutory delusions with negative self-thoughts is convincing, and is consistent with broader work showing links of negative emotion to positive symptoms of psychosis [4] including paranoia [48, 49] and with the 'social defeat' hypothesis of schizophrenia [50]. It may also link to the well-established association of living in urban areas with a greater rate of psychotic experiences [51, 52]. In a recent study, we assessed patients with persecutory delusions on a battery of psychological processes before and after being randomised to either entering a busy social urban environment or staying indoors [53]. Going outside led to a significant increase in paranoia, anxiety, depression, negative thoughts about the self, and fewer positive thoughts about the self. The increase in paranoia was partially mediated by the increases in anxiety, depression, and negative thoughts about the self. This study provides further evidence that negative affect and related processes lead to an increase in paranoia, and indicates one route via which urban environments may have an impact on psychological health.

The findings have been used to develop treatment for the common problem for patients with persecutory delusions of going outside into busy places, tested in a recent case series with fifteen patients [54]. The clear treatment implication of this work is that reducing negative thoughts about the self in patients with persecutory delusions will lead to a lessening of paranoia. In studies that have treated selfesteem and measured psychotic experiences, a reduction in delusions and hallucinations has been seen $[55,56]$. These studies have not, however, examined paranoia in particular. Studies testing clinical techniques to improve negative beliefs about the self in patients with persecutory delusions are clearly indicated [57].

\section{Interpersonal sensitivity}

'Yeh, yeh and that's the thing, I didn't realise that it was paranoia but I was terrified that people would laugh at me or ridicule me or hurt me or trick me in some way, you know, mind games became an active part of my perception' [58] 
The exact nature of negative self-cognition in paranoia remains to be determined. Assuredly, such thoughts will be related to the anxiety and depression commonly found in individuals with paranoid ideation. And negative cognitions about the self and others will be one route via which adverse events lead to paranoia [29, 59, 60]. One promising more refined specification is interpersonal sensitivity, defined as 'feeling vulnerable in the presence of others due to the expectation of criticism or rejection' [61]. Paranoid ideation can be considered as an extension of such concerns. Interpersonal sensitivity was first linked to paranoia in a series of virtual reality experimental studies [31, 62 , 63]. For instance, a study of 200 members of the general population found that people higher in interpersonal sensitivity were more likely to interpret a neutral virtual reality social environment as containing hostility from others [31]. Subsequent work has found interpersonal sensitivity to be high in patients with persecutory delusions [35] and, latterly, in those at high risk of developing psychosis [64]. Interpersonal sensitivity is positively associated with levels of anxiety and depression [65]. Longitudinal studies of interpersonal sensitivity have yet to be carried out.

A recent pilot study has provided an initial test of the effect on persecutory delusions of intervening on interpersonal sensitivity [61]. Eleven patients with persistent persecutory delusions and reporting interpersonal sensitivity took part. There was a baseline period of a fortnight, provision of six sessions of CBT focussed upon reducing interpersonal sensitivity cognitions, and a 1-month followup. Patients were stable during the baseline period but following the intervention there were large effect size reductions in both interpersonal sensitivity and the persecutory delusions which were maintained at the follow-up. However, assessments were carried out by the therapist, and there was no control group. Targeting interpersonal sensitivity in patients with persecutory delusions requires evaluation in a randomised controlled study. There is scope for greater precision in the measurement of the concept. More broadly, a topic needing sustained research is specification of the negative cognitions central to paranoia, clarifying whether there are a variety of types of negative cognitions about the self and others; qualitative surveys may be of particular help here initially. The most proximal ideation to paranoia is likely to concern vulnerability, which may stem from a number of different views about the self and others.

\section{Anomalous internal experiences}

'It isn't as much the dark that I'm afraid of now, it's the feeling of what may be in the room that I cannot see. I always feel like someone is there, and is going to either kidnap, rape, or kill me. Many times when I am home alone I feel that someone is going to break in and kill me. I always feel that someone is there' [66].

In the study of paranoia there is often an emphasis given to the misinterpretation of external events; in the attributional literature, this is typically about the occurrence of outright negative events, such as a friend being hostile [67]. Clinically, the events reported by patients are actually mostly minor and ambiguous, such as someone bumping into the person, or the looks on faces, or snippets of overheard conversations. However, it is often underappreciated that these events are common in the environment and are not always noticed or misinterpreted by patients. An alternative view is that these events only gain significance when the individual is in a subjectively unsettled state. The implication is that what is occurring is actually a misinterpretation of internal anomalous experience. The person experiences, for example, unexplained anxious arousal, or feelings of depersonalisation, or has perceptual disturbances, which go unrecognised and lead to explanations sought in the external environment. Thus, external events are fuel for the misinterpretations of the internal states.

Such anomalous experiences may be triggered by illicit drugs, poor sleep, and negative life events. There is even recent evidence that a bout of worry can cause depersonalisation in patients with persecutory delusions [68]. There are many reports of a wide-range of anomalous internal experiences in patients with psychosis [69-72]. One longstanding framing of these anomalous states in patients has been the idea that there are basic self disturbances in schizophrenia [73], and another that there is aberrant salience [74]. Those vulnerable to anomalous internal experiences are more likely to experience paranoia in an experimental setting [75]. The account of delusions arising from changes in subjective experience is also used to explain an association of hearing loss and psychotic experiences [76], which was tested in one of the first experimental studies of paranoia [77]. The appraisals of the anomalous experiences contribute to the level of distress caused [78, 79].

The creation of internal subjective states in experimental tests of paranoia is rare. A recent study used the intravenous administration of $\Delta^{9}$-tetrahydrocannabinol (THC), the principal psychoactive ingredient of cannabis, to test a causal role for anomalous experiences in paranoia [80]. A randomised, placebo-controlled test with 121 individuals from the general population reporting paranoid ideation showed that administration of THC caused the occurrence of paranoia, as assessed by virtual reality, self-report, and semi-structured interview. The THC also caused an 
increase in anomalous internal experiences and negative affect and a decrease in working memory performance. It was the increase in anomalous experience and negative affect, and not the changes in working memory, that fully mediated the increase in paranoia. Interestingly, it was not possible to disentangle the separate contributions of anomalous experiences and negative emotion, indicating common connections. Of importance now are studies that help reduce anomalous internal experiences in patients with persecutory delusions.

\section{Insomnia}

'I've even been too scared while driving to look in the rear view mirror because I knew I would 'see' the bloke who's there ready to kill me. I wouldn't sleep for hours and hours because I thought as soon as I closed my eyes there would be someone standing there when I opened them' [66].

An area of expansion in the past 5 years has been the role of sleep disturbance in the occurrence of paranoia. Indeed, sleep as a causal factor across psychiatric problems is receiving greater attention [81, 82]. The obvious routes by which problems sleeping could lead to paranoia are an increase in negative affect and in the occurrence of subtle anomalies of experience. The first systematic report on the issue found high rates of insomnia in patients with persecutory delusions [6]. Subsequent studies found substantial associations of paranoid ideation with insomnia in the general population, which were partially mediated by negative affect $[17,83]$. A longitudinal population study showed that having insomnia increased the odds by threefold of developing paranoid ideation [29]. Poor sleep has also been found to be a predictor of the persistence of existing paranoia [30]. Supporting these ideas of important causal connections between disturbed sleep and paranoia, a study of over 5,000 adolescent twin pairs found paranoia and insomnia to be associated and that there is significant overlap between the two problems in genetic and environmental risk [84].

Given that insomnia is a treatable condition [85, 86], there is an obvious potential for translation of this theoretical knowledge about the contribution of sleep to paranoia. In the only study to date, 15 patients with persistent persecutory delusions all received a four-session session CBT intervention for insomnia [87]. There were large effect size reductions in both insomnia and the delusions, which persisted at least 1 month after intervention. However, this was an unblinded, uncontrolled study. A longer CBT for insomnia intervention for patients with delusions and/or hallucinations is now being evaluated in a randomised controlled clinical trial [88]. Of course if patients with psychosis have sleep problems then these should be treated with the available evidence-based interventions, but the implication is that this will also lessen the psychotic experiences. Identification of the factors, both proximal and distal, leading to chronic sleep problems in patients with delusions would be beneficial for treatment development.

\section{Reasoning}

'When I see people laughing and talking about me I try thinking that I'm jumping to conclusions. When I see people with mobiles I've been trying to give them the benefit of the doubt-they might be taking pictures of me, but they might not. It's less distressing thinking like this...' [89]

One of the most replicated findings is the presence of 'jumping to conclusions' (JTC) being more common in patients with delusions than in non-clinical populations [90-92]. These studies have typically contained a majority of patients with persecutory delusions, so we can be confident that the bias is present in this delusion subtype although rates of JTC may be even higher in patients with grandiose delusions [93]. Jumping to conclusions, reaching certainty after limited data gathering, is considered to lead to the rapid acceptance of delusional ideas. Jumping to conclusions is associated with lower working memory capacity [94, 95], but not higher levels of need for closure [96] or intolerance of uncertainty [95]. It is present in high conviction delusional beliefs but not in high conviction anxiety beliefs [97]. In clinical groups the presence of the bias does not seem to be affected by anxiety manipulations [68, 98].

Standard assessments of JTC do not examine the type of data gathered. However, the gathering of data is highly likely to be influenced by the well-established belief confirmation bias [99], or a bias against disconfirmatory evidence [100]. Once data are gathered, the influence of experiential and analytic reasoning may be important. In the general population, higher levels of paranoia are associated with less use of analytic reasoning [101, 102]. Individuals with persecutory delusions report less use of both experiential and rational reasoning styles [102]. JTC, belief confirmation, and less use of analytic reasoning are all likely to lead not only to a strongly held delusional belief but the failure to consider alternative explanations. A failure to consider alternative explanations [103], resistance to hypothetical contradiction [10], and an unwillingness to consider the possibility of being mistaken [10] are all considered as markers of 'belief inflexibility' [104]. 


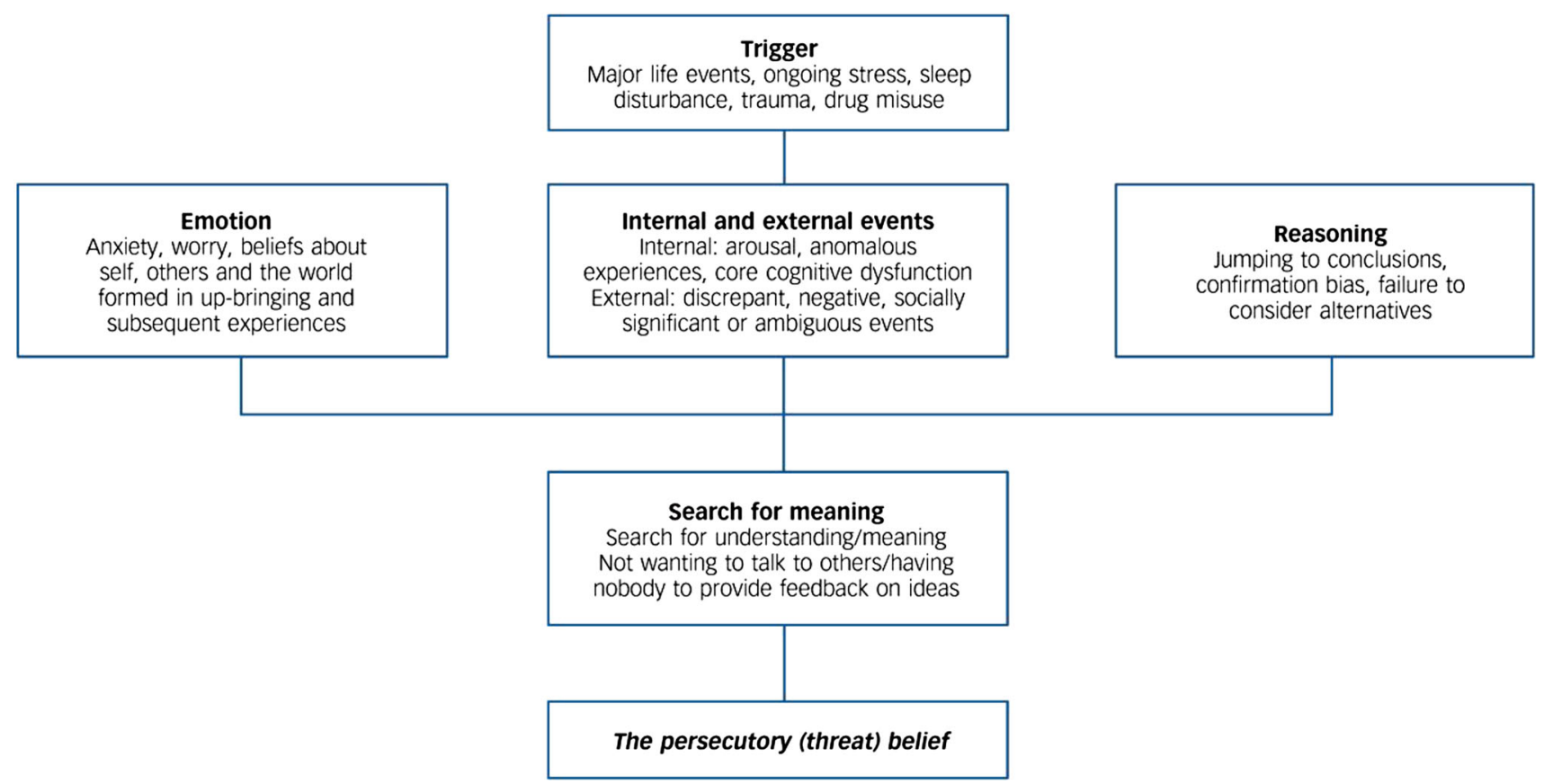

Fig. 3 Outline of factors involved in delusion formation [31]

Belief inflexibility is the reasoning process most associated with degree of conviction in delusions [105].

Attention has turned towards how this knowledge of reasoning processes in delusions can be translated into treatment. A randomised controlled trial with 154 patients with paranoia showed that a novel educational approach (metacognitive training, MCT), providing information and exercises about a number of cognitive biases found in psychosis, given within groups over eight sessions, did not have an impact on delusions [106]. A similar-sized trial suggested that MCT had benefits for patients without severe clinical delusions, i.e. with mild to moderate levels of delusional ideation [107]. These have been the two most rigorous, well-powered tests of this group reasoning educational programme, showing contrasting results. Building on this innovative work, our approach in working with people with high conviction delusions has been first to demonstrate in experimental studies short-term change in the reasoning biases [89, 108]. In a recent study, 101 patients with current delusions were randomised to a 90-min individually delivered reasoning intervention or to an attention control condition [109]. There were homework exercises over the following fortnight for patients receiving the intervention. The brief reasoning training led to significant reductions in state paranoia and improvements in reasoning: reduced JTC and increased belief flexibility. There was evidence that the increases in belief flexibility partially mediated a significant reduction in current levels of paranoia in the patients at the 2-week assessment. The study demonstrates that it is possible, at least in the short- term, to help people adjust their reasoning styles, and that this leads to change in paranoia. Belief flexibility is therefore a promising reasoning target. The next step is the development and evaluation of a longer, eight session clinical intervention aiming to achieve effective flexibility in thinking and consequent sustained change in the delusion; this is a key area for future research. Overall, the findings in our review indicate the importance of affective processes, anomalous experiences, and reasoning in the occurrence of severe paranoia (see Fig. 3).

\section{Other paths}

Perhaps the most researched psychological process in schizophrenia research has been theory of mind [110], since almost by definition the intentions of others are being misread in the content of paranoid thoughts. There is strong evidence for theory of mind difficulties being present in patients with schizophrenia [111, 112]; however, it is clear that these cognitive difficulties are most associated with negative symptoms and not paranoia [25, 26, 113]. In our recent review, in 38 clinical studies of theory of mind, the majority did not find associations with delusions in general or paranoia [26]. In three non-clinical studies there was no association of theory of mind performance and paranoia. A recent study with patients with an early episode of psychosis and non-clinical controls found no association of a dimensional paranoia measure with theory of mind performance in either group [114]. Overall, this is unsurprising. It is known that theory of mind problems is closely 
linked to cognitive neuropsychological impairments [115, 116] and that such cognitive impairments are linked with the negative rather than the positive symptoms of psychosis such as delusions [117] - the theory of mind results in schizophrenia is consistent with this pattern. Furthermore, an interesting analysis of patient conversations found theory of mind skills to be intact [118]. Our view is that in clinical settings it is possible that theory of mind difficulties is present in some patients, that when present they could exacerbate paranoid thinking, but such problems are not a key causal factor.

A topic that has gained attention but received less direct empirical scrutiny has been the hypothesis of two distinct types of paranoia: 'Poor me' and 'bad me' [119]. In the former paranoia is considered a defence against negative emotions reaching consciousness and in the latter paranoia is considered a direct reflection of conscious ideas about the self that are so extremely negative that the person believes they will be punished. In clinical populations 'Poor Me' presentations are substantially more common than 'Bad Me' [120-122]. The plausibility of there being two distinct types of paranoia with opposite causes is debateable; indeed, analysis of an epidemiological national survey indicates there to be just a single underlying paranoia dimension [15]. Importantly, the central test of the two subtypes of hypothesis has not been carried out: an examination of defence processes in each of the two types. Given that the Poor Me subtype is substantially more common, it is therefore notable that the evidence is generally inconsistent with a defence account of persecutory delusions: hypothesised defences are hard to test but the largest studies $[123,124]$ do not find defensive processing present; defensive processing has not even been found for the more obviously self-enhancing grandiose delusions [125]; while systematic literature reviews have all reported a strong direct relationship between negative emotion and delusions [26, 43, 44] which would not be predicted by a defence account. Even the presence of a hypothesised defensive externalising attributional style in individuals with persecutory delusions is a topic of debate [67]. Parsimonious explanations of negative emotion and paranoia do not need to evoke defences. In our view, the Poor Me/ Bad Me theory has helpfully highlighted one neglected aspect of the content of paranoia, i.e. people may feel they deserve to be harmed, and this is a cognition closely linked to levels of depression. As depression fluctuates so will the ideas about deserving harm, as has been reported [126]; this does not, however, indicate distinct categories. There are other aspects of the content of delusions (e.g. the individual's perceived degree of control over the situation, ideas about the power of the persecutor) [1] that may also be important in determining or be determined by emotional responses, and, equally, if dichotomised would likely lead to differences in presentation, but this would not indicate discrete subtypes. We endorse the value of identifying emotional correlates of paranoia, but see no convincing empirical evidence of distinct paranoia subtypes, and, indeed, there is evidence against such a view.

\section{New routes}

We have focussed the review upon areas which have received, to some degree, repeated empirical scrutiny. There is, however, much that remains to be investigated in this important area both for individuals' psychological health and the understanding of the broader issue of social cohesion. Extension of the work into developmental studies of mistrust in children would be especially valuable [16, 127]. This could be linked to the understanding of the metacognitive beliefs that support the adoption of paranoid beliefs [128]. There is initial promising work to take forward examining paranoia in relation to stress [129-131] and emotion regulation difficulties [132, 133]. There are interesting connections between PTSD and paranoia [30, $134,135]$ and related innovations in the treatment of psychosis [136]. There is much research relating childhood trauma and abuse to psychosis; while trauma, especially sexual abuse, has been linked to hallucinations, some recently emerging evidence links childhood neglect (such as being placed in care) specifically to paranoia [60, 137]. The precise role of imagery in paranoid fears is yet to be determined [138, 139]. How paranoia affects social functioning [140, 141], what leads to acting on delusions [142], and what are the societal factors that increase paranoia [143] are important topics for future research. Much of our work has been inspired by listening to patients and trying out strategies during psychological therapy, as indicated in the personal accounts used throughout this review. Systematic investigations of patients' views are likely to be very informative [27, 144]. How paranoia differs in causal factors from anxiety, depression, grandiosity and other related psychological problems remains to be determined $[75,93]$. It is notable that the specific neurobiology of delusions and related processing has been neglected [145], while there needs to be a concerted effort to determine the effects at the individual level on psychological processing of known social factors increasing paranoia. Given the clear evidence of advancements in understanding, arguably the greatest focus needs to be on translation into more efficacious treatments and self-management. In this work, the potential benefits of incorporating self-help [146] and technological innovations such as mobile phones [147], experience sampling methodology [148] and virtual reality [149] remains to be determined. In the future, we hope to see many more robust treatment trials focussed specifically upon patients reporting persecutory delusions. 
Acknowledgments DF is supported by a Medical Research Council (MRC) Senior Clinical Fellowship (G0902308). This study presents independent research for which PG was part-funded by the National Institute for Health Research (NIHR) Biomedical Research Centre at South London and Maudsley NHS Foundation Trust and King's College London.

\section{Conflict of interest None.}

Open Access This article is distributed under the terms of the Creative Commons Attribution License which permits any use, distribution, and reproduction in any medium, provided the original author(s) and the source are credited.

\section{References}

1. Freeman D, Garety PA, Kuipers E (2001) Persecutory delusions: developing the understanding of belief maintenance and emotional distress. Psychol Med 31:1293-1306

2. Freeman D, Garety PA (2000) Comments on the content of persecutory delusions: does the definition need clarification? $\mathrm{Br}$ J Clin Psychol 39:407-414

3. Freeman D, Startup H, Dunn G, Wingham G, Cernis E, Evans N, Lister R, Pugh K, Cordwell J, Kingdon D (2014) Persecutory delusions and psychological well-being. Soc Psychiatry Psychiatr Epidemiol 49:1045-1050. doi:10.1007/s00127-013-0803-y

4. Hartley S, Barrowclough C, Haddock G (2013) Anxiety and depression in psychosis. Acta Psychiatr Scand. doi:10.1111/ acps. 12080

5. Vorontsova N, Garety P, Freeman D (2013) Cognitive factors maintaining persecutory delusions in psychosis: the contribution of depression. J Abnorm Psychol 122:1121-1131

6. Freeman D, Pugh K, Vorontsova N, Southgate L (2009) Insomnia and paranoia. Schizophr Res 108:280-284

7. Weiner S (2003) First person account: living with the delusions and effects of schizophrenia. Schizophr Bull 29:877-879

8. Coid J, Ullrich S, Kallis C, Keers R, Barker D, Cowden F, Stamps R (2013) The relationship between delusions and violence. JAMA Psychiatry 70:465-471

9. Ullrich S, Coid J (2014) Personal communication, 4th June 2014

10. Wessely S, Buchanan A, Reed A, Cutting J, Everitt B, Garety P, Taylor P (1993) Acting on delusions. Br J Psychiatry 163:69-76

11. Freeman D (2011) Improving cognitive treatments for delusions. Schizophr Res 132:135-139

12. Plomin R, Haworth CMA, Davis OSP (2009) Common disorders are quantitative traits. Nat Rev Genet 10:872-878

13. Ronald A, Sieradzka D, Cardno A, Haworth C, McGuire P, Freeman D (2013) Characterization of psychotic experiences in adolescence using the Specific Psychotic Experiences Questionnaire (SPEQ): findings from a study of 500016 year old twins. Schizophr Bull. doi:10.1093/schbul/sbt106

14. Freeman D, Garety PA, Bebbington PE, Smith B, Rollinson R, Fowler D, Kuipers E, Ray K, Dunn G (2005) Psychological investigation of the structure of paranoia in a non-clinical population. Br J Psychiatry 186:427-435

15. Bebbington P, McBride O, Steel C, Kuipers E, Radovanovic M, Brugha T, Jenkins R, Meltzer H, Freeman D (2013) The structure of paranoia in the general population. $\mathrm{Br} \mathrm{J}$ Psychiatry 202:419-427

16. Wong K, Freeman D, Hughes C (2014) Suspicious young minds: Paranoia and mistrust in 8- to 14-year-olds in the UK and Hong Kong. Br J Psychiatry (in press)

17. Freeman D, McManus S, Brugha T, Meltzer H, Jenkins R, Bebbington P (2011) Concomitants of paranoia in the general population. Psychol Med 41:923-936
18. Zavos HMS, Freeman D, Haworth CMA, McGuire P, Plomin R, Cardno AG, Ronald A (2014) Consistent etiology of severe, frequent psychotic experiences and milder, less frequent manifestations: a twin study of specific psychotic experiences in adolescence. JAMA Psychiatry (in press)

19. Sieradzka D, Power RA, Freeman D, Cardno AD, McGuire P, Plomin R, Meaburn EL, Dudbridge F, Ronald A (2014) Are genetic risk factors for psychosis also associated with dimension-specific psychotic experiences in adolescence? PLoS ONE. doi:10.1371/journal.pone.0094398

20. Vázquez-Barquero JL, Lastra I, Nuñez MJC, Castanedo SH, Dunn G (1996) Patterns of positive and negative symptoms in first episode schizophrenia. Br J Psychiatry 168:693-701

21. Peralta V, Cuesta MJ (1999) Dimensional structure of psychotic symptoms: an item-level analysis of SAPS and SANS symptoms in psychotic disorders. Schizophr Res 38:13-26

22. Wigman JTW, Vollebergh WAM, Raaijmakers QAW, Iedema J, van Dorsselaer S, Ormel J, Verhulst FC, van Os J (2009) The structure of the extended psychosis phenotype in early adolescence - a cross-sample replication. Schizophr Bull. doi:10.1093/ schbul/sbp 154

23. Mackie JL (1974) The cement of the universe: a study of causation. Oxford University Press, Oxford

24. Garety P, Freeman D (1999) Cognitive approaches to delusions: a critical review of theories and evidence. Br J Clin Psychol 38:113-154

25. Freeman D (2007) Suspicious minds: the psychology of persecutory delusions. Clin Psychol Rev 27:45-457

26. Garety P, Freeman D (2013) The past and future of delusion research: from the inexplicable to the treatable. Br J Psychiatry 203:327-333

27. Startup H, Pugh K, Cordwell J, Kingdon D, Freeman D (2014) How do individuals with persecutory delusions bring worry to a close? An interpretative phenomenological analysis. Behav Cognit Psychother. doi:10.1017/S1352465813001136

28. Freeman D, Garety PA (1999) Worry, worry processes and dimensions of delusions. Behav Cognit Psychother 27:47-62

29. Freeman D, Stahl D, McManus S, Meltzer H, Brugha T, Wiles N, Bebbington P (2012) Insomnia, worry, anxiety and depression as predictors of the occurrence and the persistence of persecutory ideation. Soc Psychiatry Psychiatr Epidemiol 47:1195-1203

30. Freeman D, Thompson C, Vorontsova N, Dunn G, Carter L-A, Garety P, Kuipers E, Slater M, Antley A, Glucksman E, Ehlers A (2013) Paranoia and post-traumatic stress disorder in the months after a physical assault. Psychol Med 43:2673-2684

31. Freeman D, Pugh K, Antley A, Slater M, Bebbington P, Gittins M, Dunn G, Kuipers E, Fowler D, Garety P (2008) A virtual reality study of paranoid thinking in the general population. $\mathrm{Br} \mathrm{J}$ Psychiatry 192:258-263

32. Marinelli C, Cavanagh K, Dudley R (2013) The impact of rumination on state paranoid ideation in a nonclinical sample. Behav Ther 44:385-394

33. Bassett M, Sperlinger D, Freeman D (2009) Fear of madness and persecutory delusions. Psychosis 1:39-50

34. Morrison AP, Wells A (2007) Relationships between worry, psychotic experiences and emotional distress in patients with schizophrenia spectrum diagnoses and comparisons with anxious and non-patient groups. Behav Res Ther 45:1593-1600

35. Freeman D, Pugh K, Vorontsova N, Antley A, Slater M (2010) Testing the continuum of delusional beliefs: an experimental study using virtual reality. J Abnorm Psychol 119:83-92

36. Hepworth C, Startup H, Freeman D (2011) Developing treatments for persistent persecutory delusions: the impact of an emotional processing and metacognitive awareness (EPMA) intervention. J Nerv Ment Dis 199:653-658 
37. Hartley S, Haddock G, Vasconcelos E, Emsley R, Barrowclough C (2013) An experience sampling study of worry and rumination in psychosis. Psychol Med (Epub ahead of print)

38. Startup H, Freeman D, Garety PA (2007) Persecutory delusions and catastrophic worry in psychosis: developing the understanding of delusion distress and persistence. Behav Res Ther 45:523-537

39. Foster C, Startup H, Potts L, Freeman D (2010) A randomised controlled trial of a worry intervention for individuals with persistent persecutory delusions. J Behav Ther Exp Psychiatry 41:45-51

40. Freeman D, Dunn G, Startup H, Pugh K, Cordwell J, Mander H, Cernis E, Wingham G, Shirvell K, Kingdon D (2014) An explanatory randomised controlled trial testing the effects of cognitive behaviour therapy for worry on persecutory delusions in psychosis: the Worry Intervention Trial (WIT) (submitted)

41. Adam (2011) First person account: experiencing suspicious thoughts and paranoia. Schizophr Bull 37:653-655

42. Fowler D, Hodgekins J, Garety P, Freeman D, Kuipers E, Dunn G, Smith B, Bebbington P (2012) Negative cognition, depressed mood and paranoia: a longitudinal pathway analysis using structural equation modelling. Schizophr Bull 38:1063-1073

43. Kesting M, Lincoln T (2013) The relevance of self-esteem and self-schemas to persecutory delusions. Compr Psychiatry 54:766-789

44. Tiernan B, Tracey R, Shannon C (2014) Paranoia and selfconcepts in psychosis. Psychiatry Res 30:202-313

45. Hutton P, Kelly J, Lowens I, Taylor P, Tai S (2013) Selfattacking and self-reassurance in persecutory delusions. Psychiatry Res 205:127-136

46. Freeman D, Evans N, Lister R, Antley A, Dunn G, Slater M (2014) Height, social comparison, and paranoia: an immersive virtual reality experimental study. Psychiatry Res 218:348-352

47. Lincoln T, Hohenhaus F, Hartmann M (2013) Can paranoid thoughts be reduced by targeting negative emotions and selfesteem? An experimental investigation of a brief compassionfocussed intervention. Cognit Ther Res 37:390-402

48. Ben-Zeev D, Ellington K, Swendsen J, Granholm E (2011) Examining a cognitive model of persecutory ideation in the daily life of people with schizophrenia: a computerized experience sampling study. Schizophr Bull 37:1248-1256

49. Bentall RP, Rowse G, Shryane N, Kinderman P, Howard R, Blackwood N, Moore R, Corcoran R (2009) The cognitive and affective structure of paranoid delusions. Arch Gen Psychiatry 66:236-247

50. Selten J-P, van der Ven E, Rutten B, Cantor-Graae E (2013) The social defeat hypothesis of schizophrenia: an update. Schizophr Bull 39:1180-1186

51. Vassos E, Pedersen CB, Murray RM, Collier DA, Lewis CM (2012) Metaanalysis of the association of urbanicity with schizophrenia. Schizophr Bull 38:1118-1123

52. Heinz A, Deserno L, Reininghaus U (2013) Urbanicity, social adversity and psychosis. World Psychiatry 12:187-197

53. Freeman D, Emsley R, Dunn G, Fowler D, Bebbington P, Kuipers E, Jolley S, Waller H, Hardy A, Garety P (2014) The stress of the street for patients with persecutory delusions: a test of the symptomatic and psychological effects of going outside into a busy urban area (in revision)

54. Freeman D, Waller H, Harpur-Lewis R, Moore R, Garety P, Bebbington P, Kuipers E, Emsley R, Dunn G, Fowler D, Jolley S (2013) Urbanicity, persecutory delusions, and clinical intervention. Behav Cognit Psychother. doi:10.1017/S13524658 13000660

55. Hall PL, Tarrier N (2003) The cognitive-behavioural treatment of low self esteem in psychotic patients: a pilot study. Behav Res Ther 41:317-332
56. Lecomte T, Cyr M, Lesage A, Wilde J, Leclere C, Ricard N (1999) Efficacy of a self-esteem module in the empowerment of individuals with chronic schizophrenia. J Nerv Ment Dis 187:406-413

57. Freeman D, Freeman J (2012) You can be happy: the scientifically proven way to change how you feel. Prentice Hall Life, Harlow

58. Boyd T, Gumley A (2007) An experiential perspective on persecutory paranoia. Psychol Psychother 80:1-22

59. Bentall R, Fernyhough C (2008) Social predictors of psychotic experiences. Schizophr Bull 34:1012-1020

60. Bentall R, Wickham S, Shevlin M, Varese F (2012) Do specific early-life adversities lead to specific symptoms of psychosis? A study from the 2007 Adult Psychiatric Morbidity Survey. Schizophr Bull 38:734-740

61. Bell V, Freeman D (2014) A pilot trial of cognitive behavioural therapy for interpersonal sensitivity in individuals with persecutory delusions. J Behav Ther Exp Psychiatry. doi:10.1016/j. jbtep.2014.06.001

62. Freeman D, Slater M, Bebbington PE, Garety PA, Kuipers E, Fowler D, Met A, Read C, Jordan J, Vinayagamoorthy V (2003) Can virtual reality be used to investigate persecutory ideation? J Nerv Ment Dis 191:509-514

63. Freeman D, Garety PA, Bebbington P, Slater M, Kuipers E, Fowler D, Green C, Jordan J, Ray K, Dunn G (2005) The psychology of persecutory ideation II: a virtual reality experimental study. J Nerv Ment Dis 193:309-315

64. Masillo A, Day F, Laing J, Howes O, Fusar-Poli P, Byrne M, Bhattacharyya S, Fiori Nastro P, Girardi P, McGuire P, Valmaggia L (2012) Interpersonal sensitivity in the at-risk mental state for psychosis. Psychol Med 42:1835-1845

65. Freeman D, Dunn G, Garety PA, Bebbington P, Slater M, Kuipers E, Fowler D, Green C, Jordan J, Ray K (2005) The psychology of persecutory ideation I. J Nerv Ment Dis 193:302-308

66. Paranoid Thoughts Website. (http://www.paranoidthoughts. com)

67. Mehl S, Landsberg M, Schmidt A-C, Cabanis M, Bechdolf A, Herrlich J, Loos-Jankowiak S, Kircher T, Kiszkenow S, Klingberg S, Kommescher M, Moritz S, Müller B, Sartory G, Wiedemann G, Wittorf A, Wölwer W, Wagner M (2014) Why do bad things happen to me? Attributional style, depressed mood, and persecutory delusions in patients with schizophrenia. Schizophr Bull. doi:10.1093/schbul/sbu040

68. Freeman D, Startup H, Dunn G, Cernis E, Wingham G, Pugh K, Cordwell J, Kingdon D (2013) The interaction of affective with psychotic processes: a test of the effects of worrying on working memory, jumping to conclusions, and anomalies of experience in patients with persecutory delusions. J Psychiatr Res 47:1837-1842

69. Bunney W, Hetrick B, Bunney J, Patterson Y, Jin S, Potkin S, Sandman C (1999) Structured interview for assessing perceptual anomalies (SIAPA). Schizophr Bull 25:577-592

70. Bell V, Halligan PW, Ellis HD (2006) The Cardiff Anomalous Perceptions Scale (CAPS). Schizophr Bull 32:366-377

71. Brett C, Peters E, Johns L, Tabraham P, Valmaggia L, McGuire $P$ (2007) Appraisals of Anomalous Experiences Interview (AANEX). Br J Psychiatry 51:s23-s30

72. Černis E, Dunn G, Startup H, Kingdon D, Wingham G, Pugh K, Cordwell J, Mander H, Freeman D (2014) Depersonalisation in patients with persecutory delusions. J Nerv Ment Dis (in press)

73. Nordgaard J, Parnas J (2014) Self-disorders and the schizophrenia spectrum. Schizophr Bull. doi:10.1093/schbul/sbt239

74. Howes OD, Kapur S (2009) The dopamine hypothesis of schizophrenia: version III-the final common pathway. Schizophr Bull 35:549-562

75. Freeman D, Gittins M, Pugh K, Antley A, Slater M, Dunn G (2008) What makes one person paranoid and another person 
anxious? The differential prediction of social anxiety and persecutory ideation in an experimental situation. Psychol Med 38:1121-1132

76. Thewissen V, Myin-Germeys I, Bentall R, de Graaf R, Vollebergh W, van Os J (2005) Hearing impairment and psychosis revisited. Schizophr Res 76:99-103

77. Zimbardo P, Andersen S, Kabat L (1981) Induced hearing deficit generates experimental paranoia. Science 212:1529-1531

78. Brett C, Heriot-Maitland C, McGuire P, Peters E (2013) Predictors of distress associated with psychotic-like anomalous experiences in clinical and non-clinical populations. Br J Clin Psychol. doi:10.1111/bjc.12036

79. Ward T, Gaynor K, Hunter M, Woodruff P, Garety P, Peters E (2013) Appraisals and responses to experimental symptom analogues in clinical and nonclinical individuals with psychotic experiences. Schizophr Bull. doi:10.1093/schbul/sbt094

80. Freeman D, Dunn G, Murray R, Evans N, Lister R, Antley A, Slater M, Godlewska B, Cornish R, Williams J, Di Simplicio M, Igoumenou A, Brenneisen R, Tunbridge E, Harrison P, Harmer C, Cowen P, Morrison P (2014) How cannabis causes paranoia: using the intravenous administration of $\Delta^{9}$-tetrahydrocannabinol (THC) to identify key cognitive mechanisms leading to paranoia. Schizophr Bull (in press)

81. Harvey A, Murray G, Chandler RA, Soehner A (2011) Sleep disturbance as transdiagnostic: consideration of neurobiological mechanisms. Clin Psychol Rev 31:225-235

82. Anderson K, Bradley A (2013) Sleep disturbance in mental health problems and neurodegenerative disease. Nat Sci Sleep 5:61-75

83. Freeman D, Brugha T, Meltzer H, Jenkins R, Stahl D, Bebbington P (2010) Persecutory ideation and insomnia. J Psychiatr Res 44:1021-1026

84. Taylor M, Gregory A, Freeman D, Ronald A (2014) Do sleep disturbances and psychotic experiences in adolescence share genetic and environmental influences? (submitted)

85. Smith M, Perlis M, Park A, Smith M, Pennington J, Giles D, Buysse D (2002) Comparative meta-analysis of pharmacotherapy and behaviour therapy for persistent insomnia. Am J Psychiatry 159:5-11

86. Morin C, Vallières A, Guay B, Ivers H, Savard J, Mèrette C, Bastien C, Baillargeon L (2009) Cognitive behavioral therapy, singly and combined with medication, for persistent insomnia. JAMA 301:2005-2015

87. Myers E, Startup H, Freeman D (2011) Cognitive behavioural treatment of insomnia in patients with persecutory delusions. J Behav Ther Exp Psychiatry 42:330-336

88. Freeman D, Startup H, Myers E, Harvey A, Geddes J, Yu L-M, Zaiwalla Z, Luengo-Fernandez R, Foster R, Lister R (2013) The effects of using cognitive behavioural therapy to improve sleep for patients with delusions and hallucinations (the BEST study): study protocol. Trials 14:214

89. Waller H, Freeman D, Jolley S, Dunn G, Garety P (2011) Targeting reasoning biases in delusions. J Behav Ther Exp Psychiatry 42:414-421

90. Garety P, Hemsley D, Wessely S (1991) Reasoning in deluded schizophrenic and paranoid patients: biases in performance on a probabilistic inference task. J Nerv Ment Dis 179:194-201

91. Dudley R, John C, Young A, Over D (1997) Normal and abnormal reasoning in people with delusions. Br J Clin Psychol $36: 243-258$

92. Warman D, Lysaker P, Martin J, Davis L, Haudenschield S (2007) Jumping to conclusions and the continuum of delusional beliefs. Behav Res Ther 45:1255-1269

93. Garety P, Gittins M, Jolley S, Bebbington P, Dunn G, Kuipers E, Fowler D, Freeman D (2013) Differences in cognitive and emotional processes between persecutory and grandiose delusions. Schizophr Bull 39:629-639

94. Garety P, Joyce E, Jolley S, Emsley R, Waller H, Kuipers E, Bebbington P, Fowler D, Dunn G, Freeman D (2013) Neuropsychological functioning and jumping to conclusions in delusions. Schizophr Res 150:570-574

95. Freeman D, Startup H, Dunn G, Cernis E, Wingham G, Pugh K, Cordwell J, Mander H, Kingdon D (2014) Understanding jumping to conclusions in patients with persecutory delusions: working memory and intolerance of uncertainty. Psychol Med. doi:10.1017/S0033291714000592

96. Freeman D, Garety PA, Kuipers E, Colbert S, Jolley S, Fowler D, Dunn G, Bebbington PE (2006) Delusions and decisionmaking style: use of the Need for Closure Scale. Behav Res Ther 44:1147-1158

97. Jacobsen P, Freeman D, Salkovskis P (2012) Reasoning bias and belief conviction in obsessive-compulsive disorder and delusions. Br J Clin Psychol 51:84-99

98. So S, Freeman D, Garety P (2008) Impact of state anxiety on the jumping to conclusions delusion bias. Aust $\mathrm{N}$ Z J Psychiatry $42: 879-886$

99. Nickerson R (1998) Confirmation bias: a ubiquitous phenomenon in many guises. Rev Gen Psychol 2:175-220

100. Moritz S, Woodward T (2006) A generalized bias against disconfirmatory evidence in schizophrenia. Psychiatry Res 142:157-165

101. Freeman D, Evans N, Lister R (2012) Gut feelings, deliberative thought, and paranoid ideation. Psychiatry Res 197:119-122

102. Freeman D, Lister R, Evans N (2014) The use of intuitive and analytic reasoning styles by patients with persecutory delusions. J Behav Ther Exp Psychiatry 45:454-458. doi:10.1016/j.jbtep. 2014.06.005

103. Freeman D, Garety PA, Fowler D, Kuipers E, Bebbington P, Dunn G (2004) Why do people with delusions fail to choose more realistic explanations for their experiences? An empirical investigation. J Consult Clin Psychol 72:671-680

104. Garety PA, Freeman D, Jolley S, Dunn G, Bebbington PE, Fowler DG, Kuipers E, Dudley R (2005) Reasoning, emotions and delusional conviction in psychosis. J Abnorm Psychol 114:373-384

105. So S, Freeman D, Dunn G, Kapur S, Kuipers E, Bebbington P, Fowler D, Garety P (2012) Jumping to conclusions, a lack of belief flexibility and delusional conviction in psychosis. J Abnorm Psychol 121:129-139

106. van Oosterhout B, Krabbendam L, de Boer K, Ferwerda J, van der Helm M, Stant A, van der Gaag M (2014) Metacognitive group training for schizophrenia spectrum patients with delusions: a randomized controlled trial. Psychol Med. doi:10.1017/ S0033291714000555

107. Moritz S, Veckenstedt R, Bohn F, Hottenrott B, Scheu F, Randjbar S, Aghotor J, Köther U, Woodward T, Treszi A, Andreou C, Pfueller U, Roesch-Ely D (2013) Complementary group Metacognitive Training (MCT) reduces delusional ideation in schizophrenia. Schizophr Res 151:61-69

108. Ross K, Freeman D, Dunn G, Garety P (2011) Can jumping to conclusions be reduced in people with delusions? An experimental investigation of a brief reasoning training module. Schizophr Bull 37:324-333

109. Garety P, Waller H, Emsley R, Jolley S, Kuipers E, Bebbington P, Dunn G, Fowler D, Hardy A, Freeman D (2014) Cognitive mechanisms of change in delusions: an experimental investigation targeting reasoning to effect change in paranoia. Schizophr Bull (in press)

110. Frith C (1992) The cognitive neuropsychology of schizophrenia. LEA, Hove 
111. Brüne M (2005) “Theory of Mind” in schizophrenia. Schizophr Bull 31:21-42

112. Bora E, Pantelis C (2013) Theory of mind impairments in firstepisode psychosis, individuals at ultra-high risk for psychosis and in first-degree relatives of schizophrenia. Schizophr Res 144:31-36

113. Ventura J, Hellemann G, Thames A, Koellner V, Nuechterlein K (2009) Symptoms as mediators of the relationship between neurocognition and functional outcome in schizophrenia: a meta-analysis. Schizophr Res 113:189-199

114. Korver-Nieberg N, Fett A-K, Meijer C, Koeter M, Shergill S, Haan L, Krabbendam L (2013) Theory of mind, insecure attachment and paranoia in adolescents with early psychosis and healthy controls. Aust N Z J Psychiatry. doi:10.1177/ 0004867413484370

115. Hughes C (2002) Executive functions and development. Infant Child Psychol 11:201-209

116. Couture S, Granholm E, Fish S (2011) A path model investigation of neurocognition, theory of mind, social competence, negative symptoms and real-world functioning in schizophrenia. Schizophr Res 125:152-160

117. De Gracia Dominguez M, Viechtbauer W, Simons C, van Os J, Krabbendam L (2009) Are psychotic psychopathology and neurocognition orthogonal? A systematic review of their associations. Psychol Bull 135:157-171

118. McCabe R, Leudar I, Antake C (2004) Do people with schizophrenia display theory of mind deficits in clinical interactions? Psychol Med 34:401-412

119. Trower P, Chadwick P (1995) Pathways to defense of the self: a theory of two types of paranoia. Clin Psychol Sci Pract 2:263-278

120. Chadwick P, Trower P, Juusti-Butler T, Maguire N (2005) Phenomenological evidence for two types of paranoia. Psychopathology 38:327-333

121. Morris E, Milner P, Trower P, Peters E (2011) Clinical presentation and early care relationships in 'poor-me' and 'bad-me' paranoia. Br J Clin Psychol 50:211-216

122. Fornells-Ambrojo M, Garety $\mathrm{P}$ (2005) Bad me paranoia in early psychosis: a relatively rare phenomenon. $\mathrm{Br} \mathrm{J}$ Clin Psychol 44:521-528

123. Vázquez C, Diez-Alegria C, Hernandez-Lloreda MJ, Moreno MN (2008) Implicit and explicit self-schema in active deluded, remitted deluded, and depressed patients. Behav Ther Exp Psychiatry 39:587-599

124. Diez-Alegria C, Vazquez C, Nieto-Moreno M, Valiente C, Fuentenebro $\mathrm{F}$ (2006) Personalizing and externalizing biases in deluded and depressed patients: are attributional biases a stable and specific characteristic of delusions? $\mathrm{Br} \mathrm{J}$ Clin Psychol 45:531-544

125. Smith N, Freeman D, Kuipers E (2005) Grandiose delusions: an experimental investigation of the delusion-as-defence hypothesis. J Nerv Ment Dis 193:480-487

126. Melo S, Taylor J, Bentall R (2006) 'Poor me' versus 'bad me' paranoia and the instability of persecutory ideation. Psychol Psychother 79:271-287

127. Tone E, Davis J (2012) Paranoid thinking, suspicion, and risk for aggression: a neurodevelopmental perspective. Dev Psychopathol 24:1031-1046

128. Morrison AP, Gumley AI, Schwannauer M, Campbell M, Gleeson A, Griffin E, Gillan K (2005) The beliefs about paranoia scale. Behav Cognit Psychother 33:153-164

129. Myin-Germeys I, van Os J (2007) Stress-reactivity in psychosis: evidence for an affective pathway to psychosis. Clin Psychol Rev 27:409-424

130. Lincoln T, Peter N, Schäfer M, Moritz S (2009) Impact of stress on paranoia. Psychol Med 39:1129-1139
131. Moritz S, Burnette P, Sperber S, Köther U, Hagemann-Goebel M, Hartmann M, Lincoln T (2011) Elucidating the black box from stress to paranoia. Schizophr Bull 37:1311-1317

132. Westermann S, Lincoln T (2011) Emotion regulation difficulties are relevant to persecutory ideation. Psychol Psychother $84: 273-287$

133. Marwaha S, Broome M, Bebbington P, Kuipers E, Freeman D (2014) Mood instability and psychosis. Schizophr Bull 40:269-277

134. Campbell M, Morrison A (2007) The relationship between bullying, psychotic-like experiences and appraisals in 14-16 year olds. Behav Res Ther 45:1579-1591

135. Soosay I, Silove D, Bateman-Steel C, Steel Z, Bebbington P, Jones P, Chey T, Ivancic L, Marnane C (2012) Trauma exposure, PTSD and psychotic-like symptoms in post-conflict Timor Leste: an epidemiological survey. BMC Psychiatry 12:229. doi:10.1186/1471-244X-12-229

136. van den Berg D, van der Gaag M (2012) Treating trauma in psychosis with EMDR. J Behav Ther Exp Psychiatry 43:664-671

137. Sitko K, Bentall R, Shevlin M, O'Sullivan N, Sellwood W (2014) Associations between specific psychotic symptoms and specific childhood adversities are mediated by attachment styles. Psychiatry Res 217:202-209

138. Morrison A, Beck A, Glentworth D, Dunn H, Reid G, Larkin W, Williams S (2002) Imagery and psychotic symptoms. Behav Res Ther 40:1053-1062

139. Schulze K, Freeman D, Green C, Kuipers E (2013) Intrusive mental imagery in patients with persecutory delusions. Behav Res Ther 51:7-14

140. Combs D, Finn J, Wohlfahrt W, Penn D, Basso M (2013) Social cognition and social functioning in nonclinical paranoia. Cognit Neuropsychiatry 18:531-548

141. Roberts D, Combs D, Willoughby M, Mintz J, Gibson C, Rupp B, Penn D (2014) A randomized, controlled trial of Social Cognition and Interaction Training (SCIT) for outpatients with schizophrenia spectrum disorders. Br J Clin Psychol. doi:10. 1111/bjc. 12044

142. Keers R, Ullrich S, DeStavola B, Coid J (2014) Association of violence with emergence of persecutory delusions in untreated schizophrenia. Am J Psychiatry 171:332-339

143. Freeman D, Freeman J (2008) Paranoia: the 21st century fear. Oxford University Press, Oxford

144. Dudley R, Siitarinen J, James I, Dodgson G (2009) What do people with psychosis think caused their psychosis? A Q methodology study. Behav Cognit Psychother 37:11-24

145. Murray GK (2011) The emerging biology of delusions. Psychol Med 41:7-13

146. Freeman D, Freeman J, Garety P (2006) Overcoming paranoid and suspicious thoughts. Robinson, London

147. Ben-Zeev D, Brenner C, Begale M, Duffecy J, Mohr D, Mueser K (2014) Feasibility, acceptability, and preliminary efficacy of a smartphone intervention for schizophrenia. Schizophr Bull. doi:10.1093/schbul/sbu033

148. Kramer I, Simons C, Hartmann J, Menne-Lothmann C, Viechtbauer W, Peeters F, Schruers K, van Bemmel A, MyinGermeys I, Delespaul P, van Os J, Wichers M (2014) A therapeutic application of the experience sampling method in the treatment of depression: a randomized controlled trial. World Psychiatry 13:68-77

149. Freeman D (2008) Studying and treating schizophrenia using virtual reality (vr): a new paradigm. Schizophr Bull 34:605-610 